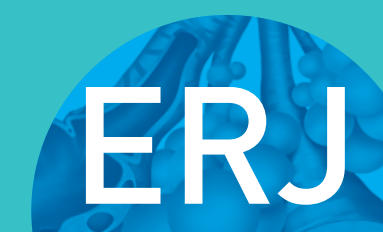

open research

\title{
Idiopathic pulmonary fibrosis in the UK: analysis of the British Thoracic Society electronic registry between 2013 and 2019
}

\author{
Lisa G. Spencer (1) ${ }^{1}$, Maria Loughenbury ${ }^{2}$, Nazia Chaudhuri ${ }^{3}$, Monica Spiteri $^{4}$ \\ and Helen Parfrey ${ }^{5}$ on behalf of the British Thoracic Society
}

Affiliations: ${ }^{1}$ Aintree University Hospital, Liverpool, UK. ${ }^{2}$ British Thoracic Society, London, UK. ${ }^{3}$ Wythenshawe Hospital, Manchester, UK. ${ }^{4}$ University Hospital of North Midlands, Stoke on Trent, UK. ${ }^{5}$ Royal Papworth Hospital, Cambridge, UK.

Correspondence: Lisa G. Spencer, British Thoracic Society, WC1N 2PL, London, UK. E-mail: lisa.spencerdaintree.nhs.uk

ABSTRACT Idiopathic pulmonary fibrosis (IPF) is a chronic, progressive and terminal interstitial lung disease (ILD) with a median survival of 3-5 years. The British Thoracic Society (BTS) established the UK IPF Registry in 2013 as a platform to collect data on clinical characteristics, treatments and outcomes for this cohort in the UK.

Between 1 January 2013 and 31 October 2019, 2474 cases were registered. Most patients were male (79\%) with a mean \pm SD age of $74 \pm 8.3$ years and $66 \%$ were ex-smokers. Over time we observed an increase in the number of patients aged over 70 years. However, we have not seen a trend towards earlier presentation as symptoms of breathless and/or cough were present for $>12$ months in $63 \%$ of the cohort. At presentation, mean \pm SD $\%$ predicted forced vital capacity (FVC) was $78.2 \pm 18.3 \%$, median $76.2 \%$ (interquartile range (IQR) $22.4 \%$ ) and transfer factor of the lung for carbon monoxide $\left(T_{\mathrm{LCO}}\right)$ 48.4 \pm 16.0 , median 47.5 (IQR 20.1). Most cases were discussed at an ILD multidisciplinary meeting, with an increase over this time in the number of cases reported as having possible usual interstitial pneumonia (UIP) pattern on high-resolution computed tomography (HRCT) thorax. We noted a reduction in the number of patients undergoing surgical lung biopsy or bronchoalveolar lavage. Although more patients were prescribed anti-fibrotic therapies from 2013 to 2019, 43\% were ineligible for treatment based upon National Institute for Health and Care Excellence (NICE) prescribing criteria. Hypertension, ischaemic heart disease, diabetes mellitus and gastro-oesophageal reflux were the most common comorbidities.

In conclusion, we have presented baseline demographics as well as diagnostic and treatment strategies from the largest single-country IPF registry, reflecting changes in UK practices over this period.

@ERSpublications

Baseline demographics, and diagnostic and treatment strategies from the largest single-country IPF registry, which reflects change in UK practice over time https://bit.ly/3kGIyls

Cite this article as: Spencer LG, Loughenbury M, Chaudhuri N, et al. Idiopathic pulmonary fibrosis in the UK: analysis of the British Thoracic Society electronic registry between 2013 and 2019. ERJ Open Res 2021; 7: 00187-2020 [https://doi.org/10.1183/23120541.00187-2020].

This article has supplementary material available from openres.ersjournals.com.

Received: 15 April 2020 | Accepted after revision: 13 Sep 2020

Copyright $\odot$ ERS 2021. This article is open access and distributed under the terms of the Creative Commons Attribution Non-Commercial Licence 4.0. 


\section{Introduction}

Idiopathic pulmonary fibrosis (IPF) is a chronic, progressive lung disease characterised by the excessive deposition of extracellular matrix in the interstitium, which ultimately leads to respiratory failure and death. Median survival is only 3 to 5 years $[1,2]$. Although there are no curative therapies for IPF, there have been considerable treatment advances during the last 6 years. The anti-fibrotic therapies, nintedanib and pirfenidone, slow disease progression and improve survival [3-7]. However, studies report that treatment-associated adverse events limit tolerability and lead to drug discontinuation in $26 \%$ of patients [8]. This suggests there is a need for more tolerable and efficacious therapies. Currently, several novel treatments are being evaluated in phase III clinical trials.

To improve the quality of life for patients with IPF, the National Institute for Health and Care Excellence (NICE) developed clinical guidelines [9] and quality standards [10] for the diagnosis and management of suspected IPF. In particular, a set of prioritised statements was designed to drive measurable quality improvements in patient care. It includes diagnosis by a multidisciplinary team meeting (MDM), managing symptoms and palliative care. The guidelines are supported by NICE technical appraisals for the anti-fibrotic therapies pirfenidone [11] and nintedanib [12], which led to the implementation of specific prescribing criteria for these treatments in the UK.

Over the last decade, there has been a significant increase in the incidence and prevalence of IPF worldwide [13]. Analysis of primary care physician databases estimate that there are 6000 new cases/year and $>32000$ patients living with IPF in the UK [14]. With IPF accounting for 1 in 100 deaths in the UK and increasing rates of hospital admissions worldwide, it is becoming a major health concern [15-17]. However, these data may not truly reflect the disease burden and utilisation of healthcare resources in the UK.

In order to provide the appropriate clinical services and treatments for this patient cohort, there is an urgent need for more representative, "real world" data concerning the incidence and prevalence of IPF in the UK. To address this, the British Thoracic Society (BTS) established a national electronic registry for patients with IPF. The UK IPF Registry enables the collection of longitudinal data on patient demographics, diagnostic investigations including lung biopsy, lung function, treatments and outcome with the long term aims to:

1. obtain a better understanding of the burden of disease, clinical characteristics and the disease course in the UK population;

2. provide information that will allow clinicians to improve patient pathways and make more informed decisions on best management strategies;

3. evaluate the impact of any changes in practice on key outcome measures such as hospitalisations and mortality;

4. facilitate research into an uncommon disease entity from a large patient population with a broad spectrum of disease severity and comorbidities.

The UK IPF Registry is funded by the British Thoracic Society. In addition, a grant from the Healthcare Quality Improvement Partnership (HQIP) (2012-2014) contributed to the initial development of the Registry and financial assistance was provided by Boehringer Ingelheim and InterMune for the enhancement of the data collection software in 2014.

We present a review of baseline data collected over the first 6 years of the UK IPF Registry and results of a survey of the participating hospital sites in the UK.

\section{Methods}

The UK IPF Registry was launched on 1 February 2013 and permitted data collection from 1 January 2013. Ethical approval was obtained (National Research Ethics Service (NRES) reference: 12/EE/0381 and renewal 17/EE/0346). The Registry is voluntary and open to all respiratory physicians in the UK. All patients diagnosed with definite or probable IPF, in accordance with American Thoracic Society, European Respiratory Society, Japanese Respiratory Society, and Latin American Thoracic Society (ATS/ERS/JRS/ ALAT) clinical practice guideline $[18,19]$, can be enrolled in the Registry provided that written consent has been obtained. Data including age, smoking history, duration of symptoms, pattern of interstitial lung disease (ILD) (usual interstitial pneumonia (UIP), possible UIP, or inconsistent with UIP) on thoracic high-resolution computed tomography (HRCT) scan and lung biopsy (UIP, probable UIP, possible UIP, or inconsistent with UIP) are collected at baseline. In addition, lung function (forced expiratory volume in $1 \mathrm{~s}\left(\mathrm{FEV}_{1}\right)$, forced vital capacity $(\mathrm{FVC})$, transfer factor of the lung for carbon monoxide $\left(T_{\mathrm{LCO}}\right)$ and transfer coefficient of the lung for caron monoxide $\left(K_{\mathrm{CO}}\right)$ ), 6-min walk test $(6 \mathrm{MWT})$, treatments, hospitalisations and outcomes are collected at baseline and at least every 12 months. Data may be included both prospectively and retrospectively, and throughout this paper "calendar years" refer to the year of the 
first clinic visit for each patient. The data are entered into a bespoke web-based platform by the hospital teams (details can be found at https://www.brit-thoracic.org.uk/quality-improvement/lung-diseaseregistries/bts-ild-registry/). All patient identifiable data are encrypted at the time of submission to the secure BTS database. Baseline data collected by 46 hospitals out of the 64 sites participating in the BTS Lung Disease Registry Programme (supplementary appendix 1) up to 31 October 2019 have been analysed. As not all datasets were complete, data have been presented as percentages rather than number of patients where applicable. All percentages have been rounded to the nearest whole number, therefore rounding errors may result in total percentages not being equal to $100 \%$. Descriptive statistics have been used to summarise the demographic and clinical characteristics at enrolment to the UK IPF Registry. Statistical analysis was performed using either the one-way analysis of variance (ANOVA) with Kruskal-Wallis or two-way ANOVA with Bonferroni correction as indicated. Data have been censored up to 31 October 2019.

Prior to 2019 the UK IPF Registry was unable to collect data pertaining to the majority of NICE Quality Standards for IPF [10]. Therefore, where additional information was required, a supplementary survey (supplementary appendix 2) was sent to all the hospitals participating in the UK IPF Registry in 2017.

The complete dataset can be accessed only by the BTS ILD Registry team, whilst individual participating sites have access to their own data at any time. Initial reviews of earlier datasets have been presented at an international conference [20].

\section{Results}

Between 1 January 2013 and 31 October 2019, 2474 incident cases of IPF were enrolled on the Registry. The Registry includes data on over 300 patients per calendar year since 2014, with 2019 data incomplete (table 1). Most patients were male (79\%) with a mean \pm SD age of $74 \pm 8.3$ years, median 74 years (interquartile range (IQR) 11) (with a range of 43 to 97 years). Over the 6.5 years of data collection, the proportion of patients aged $>70$ years has increased from 59\% in 2013 to $80 \%$ in 2019 ( $\mathrm{p}>0.05$ ) (supplementary table S1). As shown in table 1 , the majority were ex-smokers (66\%), whilst a few patients were current smokers $(4 \%)$. Information regarding first-degree relative with IPF has been collected from 2013. Our results suggest that $5 \%$ of patients have at least one first-degree relative with IPF.

Patients had a mean \pm SD of $1.8 \pm 1.2$ reported comorbidities, median 2 (IQR 2), with a range of 0 to 7 per patient. One or more comorbidities were reported in $>80 \%$ of patients (table 1). The most common comorbidities were hypertension (34\%), ischaemic heart disease (21\%), diabetes mellitus (20\%) and gastro-oesophageal reflux (18\%) (figure 1). Coexisting COPD was only reported in 6\% of patients. Of note, $12 \%$ of patients did not report any comorbidities.

The majority of patients (66\%) had experienced symptoms of exertional dyspnoea and/or cough for $>12$ months (table 2). Few patients (9\%) had symptoms for $<6$ months, whilst $40 \%$ had symptoms for $>24$ months. Over the 6 years, we have not observed any change in the proportion of patients presenting earlier ( $p>0.05$ ). At presentation, mean \pm SD \% predicted FVC was $78.2 \pm 18.3 \%$, median $76.2 \%$ (IQR $22.4 \%$ ) and $T_{\mathrm{LCO}} 48.4 \pm 16.0$, median 47.5 (IQR 20.1). Serial data show little change in FVC, but there is a trend towards lower gas transfer at initial presentation, which was not statistically significant $(\mathrm{p}>0.05)$ (table 3 and supplementary table S2). At time of enrolment to the Registry, the distribution of GAP stage was I (35\%), II (55\%) and III (10\%). As shown in table 1, we have observed a decrease in the proportion of

\section{TABLE 1 Baseline patient demographics}

\begin{tabular}{|c|c|c|c|c|c|c|c|c|c|c|}
\hline \multirow[t]{2}{*}{$\begin{array}{l}\text { Year of first } \\
\text { clinic visit }\end{array}$} & \multirow[t]{2}{*}{$\begin{array}{l}\text { Patients } \\
\text { enrolled }\end{array}$} & \multirow[t]{2}{*}{$\begin{array}{c}\text { Age years } \\
\text { mean } \pm \text { sD }\end{array}$} & \multirow[t]{2}{*}{$\begin{array}{c}\text { Male } \\
\%\end{array}$} & \multirow[t]{2}{*}{$\begin{array}{c}\text { Ex-smokers } \\
\%\end{array}$} & \multirow[t]{2}{*}{$\begin{array}{c}\text { Current } \\
\text { smokers \% }\end{array}$} & \multirow{2}{*}{$\begin{array}{c}\text { Patients with at } \\
\text { least one } \\
\text { comorbidity \% }\end{array}$} & \multirow{2}{*}{$\begin{array}{c}\text { First-degree } \\
\text { relative with IPF } \\
\%\end{array}$} & \multicolumn{3}{|c|}{$\begin{array}{c}\text { GAP } \\
\text { staging } \%\end{array}$} \\
\hline & & & & & & & & 1 & II & III \\
\hline 2013 & 160 & $71 \pm 8.7$ & 79 & 68 & 7 & 83 & 6 & 42 & 50 & 9 \\
\hline 2014 & 357 & $72 \pm 8.7$ & 75 & 65 & 5 & 82 & 5 & 37 & 50 & 12 \\
\hline 2015 & 414 & $73 \pm 8.4$ & 78 & 66 & 3 & 81 & 5 & 36 & 53 & 12 \\
\hline 2018 & 455 & $75 \pm 7.4$ & 83 & 69 & 3 & 87 & 4 & 35 & 54 & 12 \\
\hline $\begin{array}{l}2019 \text { lto } 31 \\
\text { October } 201\end{array}$ & 217 & $76 \pm 7.7$ & 77 & 62 & 1 & 82 & 5 & 30 & 64 & 6 \\
\hline
\end{tabular}

IPF: idiopathic pulmonary fibrosis. GAP: gender, age, physiology. 


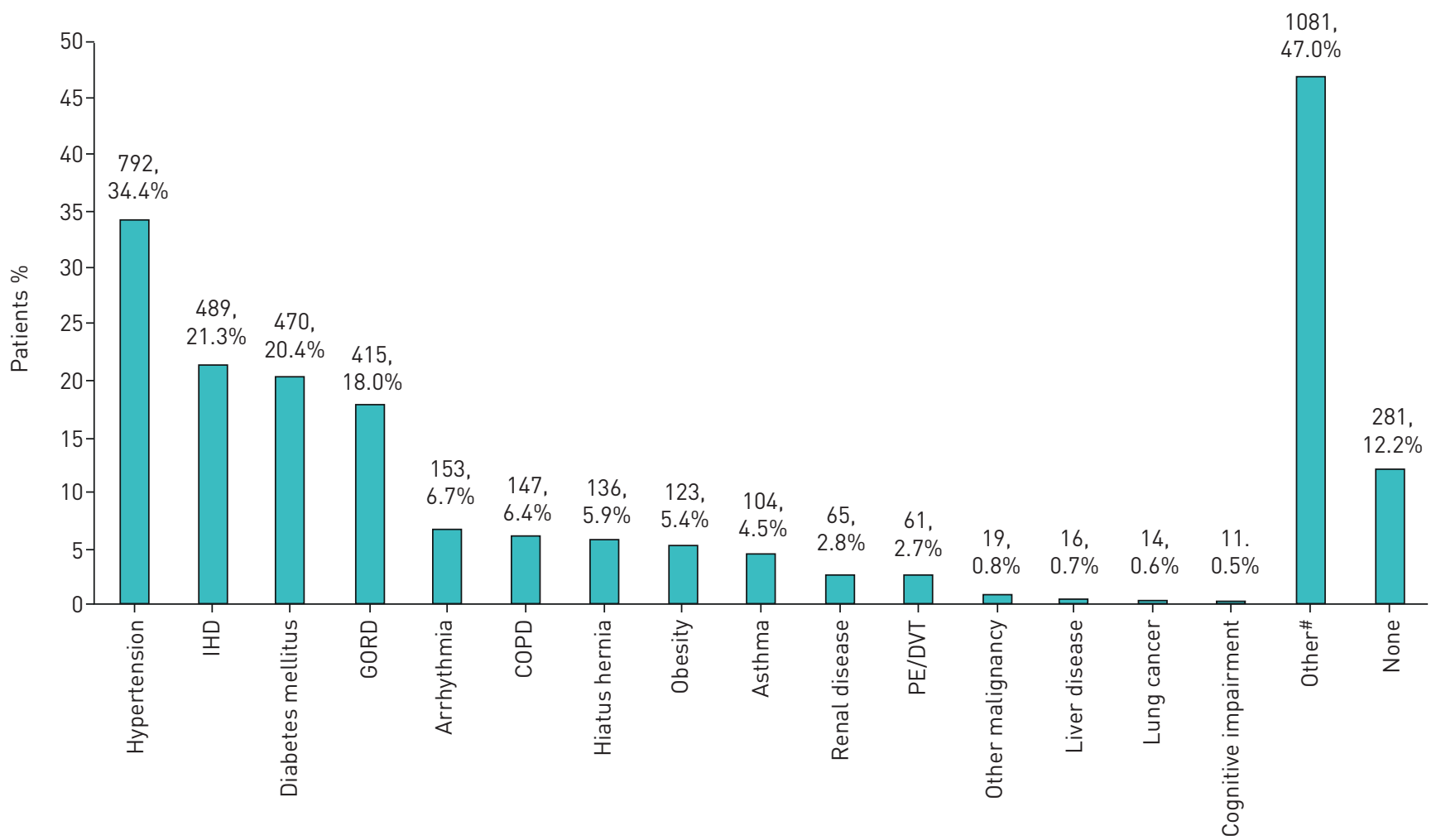

FIGURE 1 Comorbidities in patients with idiopathic pulmonary fibrosis. Data presented are the reported patient comorbidities (\% of patients) up to October 31, 2019. IHD: ischaemic heart disease; GORD: gastro-oesophageal reflux disease; PE/DVT: pulmonary embolism/deep vein thrombosis. \#: Over 200 separate conditions were listed under "other comorbidities" including osteoarthritis, hypothyroidism, several cardiac disorders (the most common included aortic stenosis, atrial fibrillation and cardiomyopathy), and a number of cancers (the most common included prostate, skin, breast, bladder, bowel and colon cancer).

patients in GAP stage I (45\% in 2013 compared to 30\% in 2019) and an increase in those in GAP stage II ( $48 \%$ in 2013 compared to $64 \%$ in 2019). Where oxygen saturation at rest (on room air) was recorded, $3 \%$ of patients had oxygen saturation measured by pulse oximetry $<88 \%, 28 \%$ of patients had $88-94 \%$ and $69 \%$ of patients had $\geqslant 95 \%$ (data not shown). Although $74 \%$ of patients felt able to perform a $6 \mathrm{MWT}$, only about a third of patients $(638 / 1812)$ completed the investigation at baseline. Of those who completed the $6 \mathrm{MWT}, 327$ individuals walked $\geqslant 300 \mathrm{~m}$, whilst 147 patients walked $<150 \mathrm{~m}$ (data not shown).

The ATS/ERS/JRS/ALAT clinical practice guideline [6] and NICE IPF diagnosis and management guideline [9] advocate MDM assessment for diagnosis of IPF. The majority (89\%) of cases diagnosed as IPF had been discussed at an ILD MDM (data not shown). Based on HRCT, patients were identified as

\section{TABLE 2 Symptom duration}

\begin{tabular}{|c|c|c|c|c|c|c|}
\hline Year & $<6$ months & 6-12 months & $12-24$ months & $>24$ months & No symptoms & Not known \\
\hline Unknown & $40(21)$ & $13(7)$ & 6 (3) & 25 (13) & $6(3)$ & $11(6)$ \\
\hline 2013 & $15(24)$ & $20(32)$ & $26(41)$ & 34 (54) & $1(2)$ & $4(6)$ \\
\hline 2015 & $8(32)$ & 22 (89) & $22(90)$ & $44(180)$ & $2(6)$ & $4(16)$ \\
\hline 2016 & 8 (27) & $25(79)$ & $22(71)$ & 38 (122) & $4(13)$ & $3(10)$ \\
\hline 2017 & $8(31)$ & 24 (89) & $21(80)$ & $43(161)$ & $2(6)$ & $3(11)$ \\
\hline
\end{tabular}

Data are presented as \% (n). " : p>0.05 comparing the results by year for each symptom duration was calculated using the two-way ANOVA with Bonferroni correction; cases where the year of presentation was unknown were excluded. 
TABLE 3 Proportion of patients with lung function based upon forced vital capacity (FVC) and transfer factor of the lung for carbon monoxide ( $\left.T_{\mathrm{LCO}}\right)$

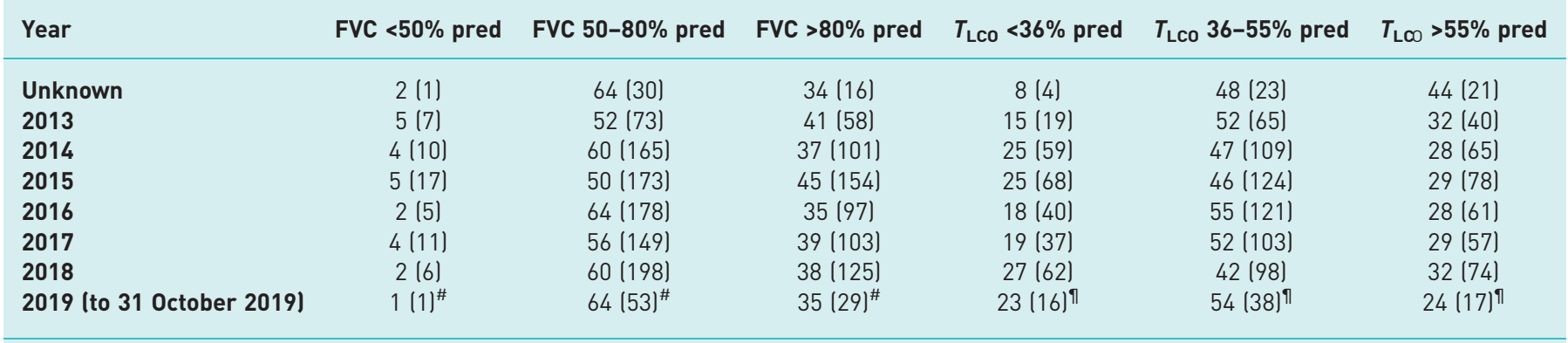

Data are presented as $\%(n) .{ }^{\#}: p>0.05$ comparing the results by year for $\%$ predicted FVC distribution was calculated using the two-way ANOVA with Bonferroni correction; cases where the year of presentation was unknown were excluded. ": $p>0.05$ comparing the results by year for $\%$ predicted $T_{\text {LCo }}$ was calculated using the two-way ANOVA with Bonferroni correction; cases where the year of presentation was unknown were excluded.

having a diagnosis of definite UIP pattern in $44 \%$ of cases, possible UIP in $50 \%$ and findings inconsistent with UIP in 4\% in accordance with the ATS/ERS/JRS/ALAT 2011 consensus statement [18]. Over time, we observed a slight increase in the proportion of patients being classified with possible UIP ( $p>0.05)$ and a comparable decrease in those with definite UIP pattern on HRCT $(\mathrm{p}>0.05)$ (table 4). More importantly, our data show a reduction in the number of patients undergoing a diagnostic surgical lung biopsy from $16 \%$ in 2013 to $3 \%$ in 2018 , which was not statistically significant ( $\mathrm{p}=0.42$ ) (table 5). Of those who had a lung biopsy, $88 \%$ had either UIP or probable UIP histology (table 4). Unclassifiable fibrosis was diagnosed in a small proportion (4\%) of this cohort. A similar decline in the proportion of patients undergoing bronchoalveolar lavage (12\% in 2013 compared to $4 \%$ in 2018, p=0.43) has also been noted (table 5).

In England and Wales, NICE has established specific treatment criteria for IPF, and anti-fibrotic therapies can be used in patients with FVC $50-80 \%$ predicted $[11,12]$. From our data, only $57 \%$ of patients are eligible for anti-fibrotic therapy (data not shown). In particular $38 \%$ of those patients currently ineligible for anti-fibrotic therapy have an FVC $>80 \%$ (data not shown). Our data show an increased use of anti-fibrotic therapies from 2013 to 2019 (table 6). Furthermore, there has been an increase in use of nintedanib between 2016 and 2019, which was not statistically significant $(p=0.42$ ). In total, $44 \%$ of the cohort has received anti-fibrotic therapies (data not shown), but this is less than the $57 \%$ of patients who fulfil eligibility criteria for these treatments. At first clinic visit $3 \%$ of patients with IPF (53 out of 1809) were referred for lung transplant and 63\% were deemed unsuitable. Of those referred at first clinic visit, seven patients were recorded as having received a transplant, either initially or at follow-up (follow-up data were available for $43 \%$ of patients referred for transplant at first clinic visit).

\section{TABLE 4 Idiopathic pulmonary fibrosis diagnostic criteria}

\begin{tabular}{|c|c|c|c|c|c|c|c|}
\hline \multirow[t]{2}{*}{ Year } & \multicolumn{3}{|c|}{ HRCT pattern } & \multicolumn{4}{|c|}{ Histological pattern } \\
\hline & $\begin{array}{l}\text { Definite } \\
\text { UIP }\end{array}$ & $\begin{array}{l}\text { Possible } \\
\text { UIP }\end{array}$ & $\begin{array}{c}\text { Inconsistent with } \\
\text { UIP }\end{array}$ & UIP & $\begin{array}{l}\text { Probable } \\
\text { UIP }\end{array}$ & $\begin{array}{l}\text { Possible } \\
\text { UIP }\end{array}$ & $\begin{array}{c}\text { Unclassifiable } \\
\text { fibrosis }\end{array}$ \\
\hline 2013 & 51.1 & 41.7 & 7.2 & 68.2 & 27.3 & 4.5 & 0.0 \\
\hline 2014 & 46.7 & 46.3 & 7.0 & 65.5 & 24.1 & 6.9 & 3.4 \\
\hline 2015 & 40.1 & 55.6 & 4.3 & 70.3 & 8.1 & 10.8 & 10.8 \\
\hline 2018 & 46.0 & 51.9 & 2.2 & 55.6 & 22.2 & 11.1 & 11.1 \\
\hline $\begin{array}{l}2019 \text { (to } 31 \\
\text { October 2019) }\end{array}$ & $46.8^{\#}$ & $43.0^{\#}$ & $10.1^{\#}$ & $100.0^{\pi}$ & $0.0^{\pi}$ & $0.0^{\pi}$ & $0.0^{\pi}$ \\
\hline
\end{tabular}

Data are presented as \% patients. HRCT: high-resolution computed tomography; UIP: usual interstitial pneumonia. ${ }^{\#}$ : p>0.05 comparing the results by year for HRCT pattern was calculated using the two-way ANOVA with Bonferroni correction; cases where the year of presentation was unknown were excluded. ": p>0.05 comparing the results by year for histological pattern was calculated using the two-way ANOVA with Bonferroni correction; cases where the year of presentation was unknown were excluded. 


\section{TABLE 5 Trends in diagnostic investigations}

\section{Year}

Unknown
2013

2014

2015

2016

2017

2018

2019 (to 31 October 2019)
Surgical lung biopsy

21.6
16.1
10.5
11.2
8.1
5.1
2.8
$1.2^{\#}$

21.6

10.5

11.2

8.1

5.1

2.8

$1.2^{\#}$
Bronchoalveolar lavage
11.8
11.9
4.0
2.2
4.5
3.9
3.8
$1.3^{\#}$

Data are presented as \% patients. ${ }^{\#}$ : comparing the proportion of patients undergoing surgical lung biopsy $(p=0.42)$ and undergoing bronchoalveolar lavage $(p=0.43)$ by year; statistical analysis performed using one-way ANOVA with Kruskal-Wallis. Cases where the year of presentation was unknown were excluded.

In terms of supportive therapies, $21 \%$ of patients with IPF were receiving supplemental oxygen therapy, including short burst, ambulatory and continuous oxygen (table 6). We have observed an increase in the assessment and referral for pulmonary rehabilitation from 55\% in 2013 to $84 \%$ in 2019 ( $\mathrm{p}=0.42$ ). Data have been collected on referral to palliative care since 2017 , with $62 \%$ of patients referred for palliative care services at first clinic visit. In late 2019 the UK IPF Registry dataset was updated to capture assessment of palliative care needs.

The UK IPF Registry dataset was initially designed before the NICE Quality Standards for IPF [10] were published, and questions were updated in late 2019 to ensure information was captured against each standard. In June 2017 a survey was circulated to the 52 participating sites, collecting information which was not available through the Registry at that time. Responses were collected from 15 sites (29\%), with $74 \%$ reporting a specialist nurse was "always" or "sometimes" present at the ILD clinic. Additionally, 73\% of sites reported having nurse-led ILD clinics.

From data censored to 31 October 2019, the median survival was 496.5 days (ranging from 16 days to 3940 days) and mortality rate 10\%. IPF disease progression or acute exacerbation accounted for $55 \%$ of deaths (figure 2). Although $1 \%$ of patients had concomitant lung cancer at time of presentation, this was associated with a worse prognosis and accounted for $3 \%$ of all IPF deaths.

\section{Discussion}

Patient registries offer a unique opportunity to collect longitudinal data on uncommon diseases, such as IPF. They may help to identify specific clinical phenotypes and understand current practices in diagnosis and treatment stratification, ultimately leading to a more personalised medicine approach to individual patient care. Over the 6 years since it was established, the UK IPF Registry has collected baseline clinical data on over 2400 patients, which is the largest single-country IPF registry reported to date. Unlike clinical trials,

\section{TABLE 6 Treatments for idiopathic pulmonary fibrosis at first clinic visit}

\begin{tabular}{|c|c|c|c|c|c|}
\hline Year & Pirfenidone & Nintedanib & $\begin{array}{l}\text { Referred for lung } \\
\text { transplantation }\end{array}$ & Oxygen & $\begin{array}{l}\text { Pulmonary rehabilitation, } \\
\text { assessed and/or referred }\end{array}$ \\
\hline Unknown & 14 (7) & $12(6)$ & $6(3)$ & 18 (9) & $100(4)$ \\
\hline 2014 & 40 (111) & $4(10)$ & $6(17)$ & $22(62)$ & $54(21)$ \\
\hline 2015 & $33(111)$ & $13(45)$ & $4(14)$ & $22(76)$ & $46(31)$ \\
\hline 2016 & 20 (57) & $21(59)$ & $2(5)$ & $16(45)$ & $60(75)$ \\
\hline 2019 (to 31 October 2019) & $29(23)^{\#}$ & $33(26)^{\#}$ & $1(1)^{\#}$ & $7(6)^{\#}$ & $84(70)^{\#}$ \\
\hline
\end{tabular}

Data are presented as \% (n). ${ }^{\#}$ : $p=0.42$ comparing treatments at first clinic visit by year; statistical analysis performed using the one-way ANOVA with Kruskal-Wallis. Cases where the year of presentation was unknown were excluded. " : data were only collected in this format from January 2017; data are available from 2013 because records may be entered retrospectively. 


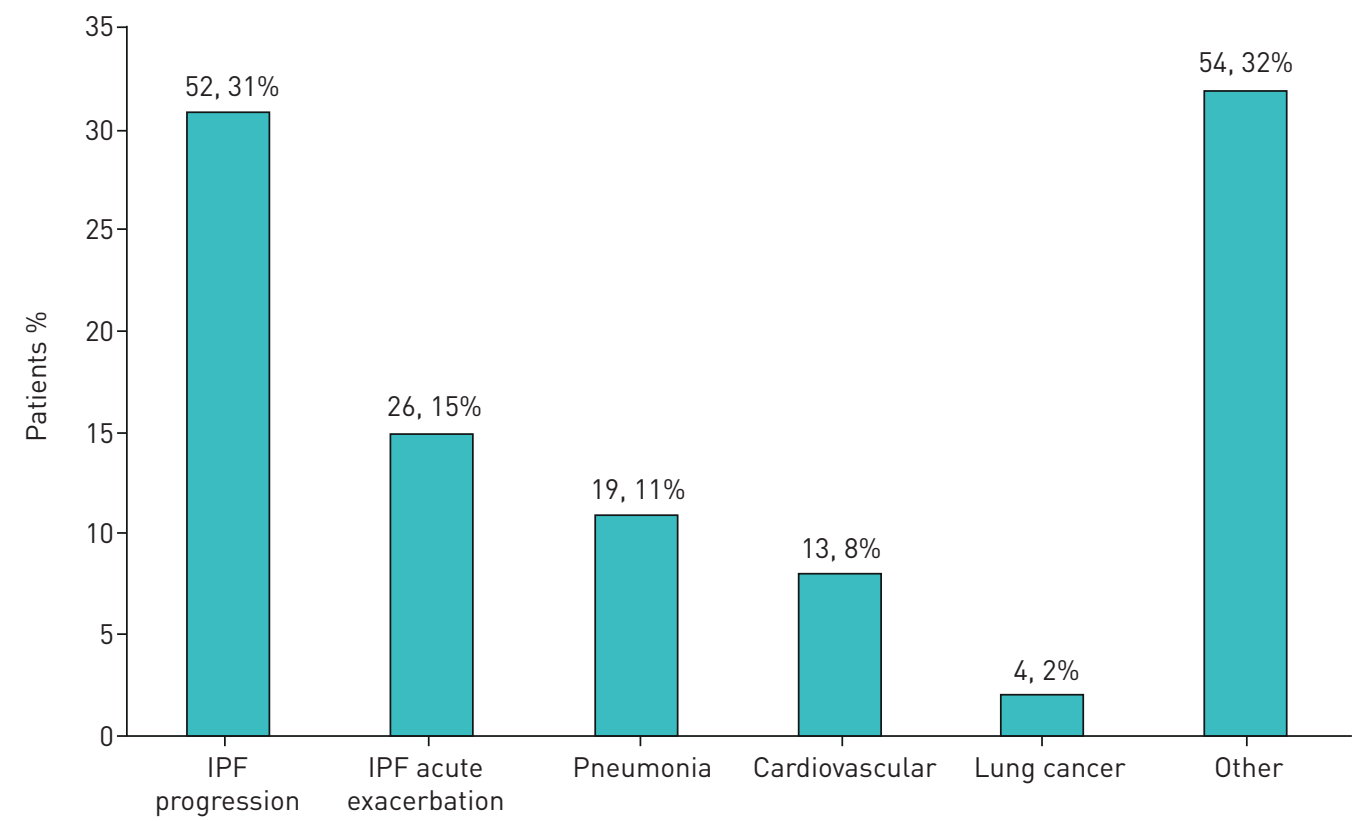

FIGURE 2 Cause of death in patients with idiopathic pulmonary fibrosis (IPF). Data presented are the reported cause of death ( $\mathrm{n}, \%$ of patients) up to 31 October 2019. 20 separate causes of death were listed under "other" including a number of cancers (lung, bladder, prostate and stomach cancer), multi-organ failure and sepsis. In 30 cases, the cause of death was not known.

which exclude patients based upon lung function impairment, comorbidities and concurrent medications, this retrospective analysis provides a more "real world" overview of patients with IPF in the UK.

Our baseline demographics are similar to other reported registries $[5,19,21-26]$ as well as the inclusion criteria for the Assessment of Pirfenidone to Confirm Efficacy and Saftey in IPF (ASCEND) [3] and Efficacy and Safety of Nintednaib in IPF (INPULSIS) [4] clinical trials with patients being predominantly male, over the age of 60 years and ex-smokers. However, our mean $\pm \mathrm{SD}$ age at enrolment is higher than that reported by a number of worldwide registries (67-71 \pm 8 years) $[5,19-25]$ but comparable to the FinnishIPF Registry (73 \pm 9.0 years) [27]. This may be explained, in part, by an increase in the number and proportion of individuals aged 79 years or more diagnosed with IPF in our Registry. It may also reflect delays in presentation to primary care, referral to a respiratory physician or diagnosis as $\sim 40 \%$ of patients had symptoms for at least 2 years at time of inclusion to the UK IPF Registry. Delays in diagnosis may arise due to lack of awareness regarding IPF [28] and misdiagnosis with another respiratory disorder, as well as the complexities of the diagnostic pathway for IPF [29], although these cannot be evaluated using our Registry data.

The baseline lung function is analogous to that reported in the Australian IPF Registry (AIPFR) [5], The Belgian and Luxembourg Prospective IPF Registry (PROOF) [22], Spanish National IPF Registry (SEPAR) [26] and European Multipartner IPF Registry (EMPIRE) [24] registries as well as the INPULSIS study [4]. Although the gas transfer measurement was comparable, the mean FVC reported in our Registry was higher than that from the European IPF Registry (eurIPFreg) [23], United States IPF National Registry (IPF-PRO) [19] and ASCEND study [3]. Moreover, our cumulative data show that whilst the per cent predicted FVC at inclusion is relatively unchanged, the $T_{\mathrm{LCO}}$ value has reduced. From our data, the higher FVC and lower gas transfer values cannot be explained by an increase in the proportion of patients with coexisting emphysema. It may reflect more severe pulmonary fibrosis as supported by an increase in the proportion of patients in GAP stage II or more over this time. But other factors, such as pulmonary hypertension, can contribute to a reduction in gas transfer. However, Registry data concerning the presence of pulmonary hypertension are insufficient to draw any conclusions. Only a third of patients had performed a $6 \mathrm{MWT}$ at time of enrolment to the Registry. Given the limited data, we are unable to interpret these results. The Registry does not collect information about why the 6MWT was not performed. It may be due to lack of resources for testing and/or patient choice.

We identified a family history of IPF in $<10 \%$ of cases, which is similar to that reported by the Finnish IPF Registry (FinnishIPF) [27], SEPAR [26] and PROOF [22] registries. However, a higher percentage of an affected first-degree relative has been observed in other registries $[5,23]$. 
Data from patient registries have confirmed the presence of comorbidities in IPF and their association with poorer quality of life [30]. Our findings show that the majority of patients with IPF have a mean of 1.8 comorbidities. The most prevalent comorbidities were cardiovascular, including hypertension and ischaemic heart disease, and gastro-oesophageal reflux disease. These results are similar to those from the AIPFR [5], PROOF [22], eurIPFreg [23] and German IPF Registry (INSIGHTS) [21] IPF registries. In contrast, the prevalence of diabetes mellitus was greater (38\%) in the FinnishIPF Registry [27] versus $15-22 \%$ as described by BTS, as well as European and Australian registries [5, 21-23, 26]. These comorbidities were collected at time of enrolment to the UK IPF Registry, and longitudinal data are required to determine their impact on treatment strategies, hospitalisations and mortality.

Our results demonstrate that the majority of patients had symptoms of exertional breathlessness and/or cough for 12 months or more, prior to diagnosis and enrolment on the UK IPF Registry. Similar findings have been reported by other registries, such as eurIPFreg where the average time between the onset of symptoms and diagnosis of IPF was 21.8 months [23]. Determining the time from onset of symptoms to diagnosis of IPF can be confounded by several factors. It is well recognised that there may be a prolonged period, up to 4-5 years, between symptom onset and diagnosis [31]. In addition, patients may be at different stages in their disease course at the time of enrolment, and it may be difficult to ascertain precisely when their symptoms first started. Although patients may have been diagnosed with IPF by local physicians prior to referral to a specialist ILD centre, the time taken to refer to an ILD service can be very variable. Overall $90 \%$ of Registry cases were submitted from specialist centres, where patient referral may be delayed until the FVC is within the treatment criteria defined by NICE. Hence the date of assessment or MDM is unlikely to be equivalent to the date of diagnosis. Furthermore, we have not observed an increase in the proportion of patients presenting with shorter symptom duration over the course of the UK IPF Registry. This suggests that there is a need for education and raising awareness about the condition to promote earlier diagnosis, especially amongst primary care physicians who frequently undertake the initial patient assessment.

The gold standard for diagnosis of IPF is MDM [6]; however, not all patients were reviewed at MDM. This may reflect that patients can be enrolled by secondary care teams without evaluation in a specialist centre MDM. In comparison to other registries, the UK IPF Registry has a higher number of cases being reviewed at MDM. This difference may be due to easier access to a specialist ILD MDM as the majority of the patients were enrolled from ILD centres who have regular MDMs. In comparison, limited access to local ILD multidisciplinary meetings was a major concern for the Australian IPF Registry who implemented a central MDM review to overcome this barrier [5].

Since the UK IPF Registry was established, there has been an update to the clinical practice guidelines [32], which reflects changes in the radiological diagnostic criteria for IPF [33]. However, the data presented have been collected using the previous ATS/ERS/JRS/ALAT guideline [18]. They show an increase in the number of cases reported with a possible UIP pattern on thoracic HRCT scan over this time. As the Registry does not independently evaluate the thoracic HRCT scans, these results suggest an increased awareness of the spectrum of radiological characteristics and clinical predictors of IPF $[33,34]$ amongst ILD physicians and MDM in the UK. From late 2019 onwards, the UK IPF Registry dataset was modified to reflect the newer clinical practice guidelines [32].

In the setting of possible UIP pattern pulmonary fibrosis, the clinical guideline advises lung biopsy provided there are no contraindications. Despite these recommendations, the surgical lung biopsy rate $(<10 \%)$ was lower than the $20-30 \%$ reported by the IPF-PRO, PROOF, FinnishIPF, AIPFR and Swedish IPF registries $[5,19,22,25,27]$. Furthermore, we observed a reduction in surgical lung biopsy rates over this time. This could not be explained by an increase in bronchoalveolar lavage or use of cryobiopsy, as this was not routinely available at most enrolling sites. A similar decline in open or thoracoscopic lung biopsy procedures has been observed by the eurIPFreg [23]. The UK IPF Registry does not collect information as to why investigations such as surgical lung biopsy or bronchoalveolar lavage were not performed. We speculate that the decline in lung biopsy indicates a growing awareness and recognition of the risk of acute exacerbation and progression of pulmonary fibrosis associated with the procedure [35] amongst specialist ILD MDMs in the UK. In addition, the rates of bronchoscopy and analysis of bronchoalveolar lavage fluid (BALF) vary widely across registries, with analysis of BALF conducted in $85 \%$ of patients in eurIPFreg [23], $62 \%$ of patients in INSIGHTS-IPF [21], about $20 \%$ of patients in AIPFR [5] and 10\% of patients in the IPF-PRO Registry [19]. This is in contrast to the lower number of bronchoalveolar lavage (4\%) reported here. Although bronchoscopy is available at most UK IPF Registry enrolling sites, not all services can provide differential cell count analysis of the BALF. Furthermore, other factors such as comorbidities and patient and/or physician preference may influence a lower uptake of bronchoscopy in the diagnostic pathway for IPF in the UK. 
Over the duration of the UK IPF Registry, there has been an increase in the use of anti-fibrotic therapies at time of enrolment supporting a change in patient management. Our data also show differences in prescribing practice which likely reflects the availability of these therapies in the UK, as pirfenidone was first approved for IPF in 2013 [11], but it was not until 2016 when access to nintedanib was granted by NICE [12]. Of note, not all eligible patients with IPF were receiving anti-fibrotic therapy. This may be due to several reasons including patient choice and contraindications to treatment. As only specialist ILD centres can prescribe anti-fibrotic therapies in England and Wales, any eligible patients enrolled by secondary care sites will not have access to these treatments until they are reviewed at a prescribing centre.

The UK IPF Registry confirmed that many patients are receiving supportive care. Approximately a quarter of patients have supplemental oxygen therapy at baseline, which is similar to that reported in the IPF-PRO Registry [19]. This has not significantly changed over the 6 years of the Registry. However, the observed increased use of pulmonary rehabilitation may reflect implementation of NICE Quality Standards for IPF [10] as well as the accumulating evidence that pulmonary rehabilitation improves quality of life and symptoms in patients with IPF [36]. As reported by other registries, the proportion of patients assessed and listed for lung transplantation remains small [19,23]. Given the stringent suitability criteria, lung transplantation is only an option for a highly selected cohort of IPF patients.

The published registries have confirmed the high mortality associated with IPF. In support of this, the eurIPFreg reported a mortality rate of 38\% during the follow-up period [23], the INSIGHTS-IPF Registry reported that $26.7 \%$ of patients died during follow-up [30] and $15 \%$ of patients died within 30 months as detailed by the IPF-PRO Registry [19]. Advanced age and worse lung function (FVC and $T_{\mathrm{LCO}}$ ) have consistently been shown to be predictors of mortality in IPF registries [19]. A more recent analysis of data from 662 patients in the IPF-PRO Registry demonstrated that use of supplemental oxygen at rest was the strongest predictor of mortality over a follow-up period of 30 months [19]. Compared to other registries, the mortality rate reported here is lower. It is unlikely to be a true representation of IPF mortality in the UK as the survival data are incomplete. Longitudinal follow-up data are required for a more precise assessment of mortality. Hence we are not able to draw specific conclusions about IPF-related mortality in the UK in comparison to other worldwide registries.

The UK IPF Registry dataset has been modified in order to capture information relating to the NICE Quality Standards for IPF.

There are several limitations to these data, in particular incomplete datasets. In order to address this, the data have been presented as percentages and absolute numbers of patients shown where applicable.

In conclusion, we have reported the largest single-country IPF cohort, which may provide insights into the phenotypes and natural course of the disease as well as changes in the clinical management of these patients. Our results have identified key changes in the diagnostic evaluation of patients with suspected IPF in the UK between 2013 and 2019 suggesting a better understanding of the clinical and radiological predictors of IPF. We have also observed vital improvements in patient care. How these changes will impact longer-term outcomes such as hospitalisation and survival, as well as informing development of healthcare policies, remains to be determined. In addition, our findings have highlighted critical areas to target for research, especially the need for earlier diagnosis. Longitudinal data are essential to achieve these aims of the Registry. However ongoing challenges remain, in particular how to maintain the quality and completeness of the Registry data, which present both resourcing and administrative challenges.

Acknowledgements: The authors would like to thank the BTS ILD Registry Steering Group. The authors would also like to thank the participating hospitals, as listed in appendix 1, who have enrolled patients to the UK IPF Registry.

BTS ILD Registry collaborators: Christine Fiddler (Addenbrooke's Hospital, Cambridge University Hospitals NHS Foundation Trust, Cambridge), Gareth Walters and Sherwood Burge (Birmingham Heartlands Hospital, Heart of England NHS Trust, Birmingham), Melanie Caswell (Blackpool Victoria Hospital, Blackpool Teaching Hospitals NHS Foundation Trust, Blackpool), Simon Hart and Mark Major (Castle Hill Hospital, Hull and East Yorkshire Hospitals NHS Trust, Cottingham), David Adeboyeku (Central Middlesex Hospital, London North West Healthcare NHS Foundation Trust, London), Ananthakrishnan Raghuram (Cheltenham General Hospital, Gloucestershire Hospitals NHS Foundation Trust, Cheltenham), Ling-Pei Ho (Churchill Hospital, Oxford University Hospitals NHS Trust, Oxford), Arvind Rajasekaran (City Hospital, Sandwell and West Birmingham NHS Trust, Birmingham), Aravind Ponnuswamy (Countess of Chester Hospital, Countess of Chester Hospital NHS Foundation Trust, Chester), Stephen Cowie (Darlington Memorial Hospital, County Durham and Darlington NHS Foundation Trust, Darlington), Mamoun Ibrahim (Ealing Hospital, London North West Healthcare NHS Foundation Trust, London), Christine O'Brien (George Eliot Hospital, George Eliot Hospital NHS Trust, Nuneaton), Jane Scullion (Glenfield Hospital, University Hospitals of Leicester, Leicester), Andrew White and Henry Steer (Gloucestershire Royal Hospital, Gloucestershire Hospitals NHS Foundation Trust, Gloucester), Dimitrina Petkova (Good Hope Hospital, Heart of England NHS Trust, Sutton Coalfield), Surinder Birring and Boris Lams (Guy's Hospital, Guy's and St Thomas' NHS Foundation Trust, London), Robina Coker (Hammersmith Hospital, Imperial College Healthcare NHS Trust, London), Robert Buttery (Hinchingbrooke Hospital, Hinchingbrooke Health Care NHS Trust, Huntingdon), Hannah Fletcher (King's College 
Hospital, King's College Hospital NHS Foundation Trust, London), John Hutchinson (King's Mill Hospital, Sherwood Forest Hospitals NHS Foundation Trust, Sutton-in-Ashfield), Emad Hilal (Liverpool Heart and Chest Hospital, Liverpool Heart and Chest Hospital NHS Foundation Trust, Liverpool), Janet Fallon (Musgrove Park Hospital, Taunton \& Somerset NHS Foundation Trust, Taunton), Ahmed Fahim (New Cross Hospital, Royal Wolverhampton Hospitals NHS Trust, Wolverhampton), Andrew Wilson (Norfolk and Norwich University Hospital, Norfolk \& Norwich University Hospitals NHS Foundation Trust, Norwich), Georgina Hands and Alison Moody (North Devon District Hospital, Northern Devon Healthcare NHS Trust, Barnstaple), Stephen Bianchi (Northern General Hospital, Sheffield Teaching Hospitals NHS Foundation Trust, Sheffield), Bhagyashree Jayaraman (North Middlesex University Hospital, North Middlesex University Hospital NHS Trust, London), Arnab Datta (Northwick Park Hospital, London North West Healthcare NHS Foundation Trust, London), William Chang (Nottingham City Hospital, Nottingham University Hospitals NHS Trust, Nottingham), Jonathan Naylor (Peterborough City Hospital, Peterborough \& Stamford Hospitals NHS Foundation Trust, Peterborough), K. Suresh Babu (Queen Alexandra Hospital, Portsmouth Hospitals NHS Trust, Portsmouth), Robert Allcock (Queen Elizabeth Hospital, Gateshead Health NHS Foundation Trust, Gateshead), Philip Molyneaux (Royal Brompton Hospital, Royal Brompton and Harefield NHS Foundation Trust, London), Srividya Narayan (Royal Derby Hospital, University Hospitals of Derby and Burton NHS Foundation Trust, Derby), Michael Gibbons (Royal Devon and Exeter Hospital, Royal Devon and Exeter Foundation NHS Trust, Exeter), Katie Ward (Royal Free Hospital, Royal Free London NHS Foundation Trust, London), Timothy Gatheral and Claire Squires (Royal Lancaster Infirmary, University Hospitals of Morecambe Bay NHS Foundation Trust, Lancaster), Ian Forrest (Royal Victoria Infirmary, Newcastle upon Tyne Hospitals NHS Foundation Trust, Newcastle upon Tyne), Mazhar Chaudri (Russells Hall Hospital, The Dudley Group NHS Foundation Trust, Dudley), Salman Ghani (Solihull Hospital, Heart of England NHS Trust, Solihull), Katherine Spinks (Southampton General Hospital, University Hospital Southampton NHS Foundation Trust, Southampton), Huzaifa Adamali (Southmead Hospital, North Bristol NHS Trust, Bristol), Paul Beirne (St James' University Hospital, Leeds Teaching Hospital NHS Trust, Leeds), Melissa Wickremasinghe (St Mary's Hospital, Imperial College Healthcare NHS Trust, London), Joanna Porter (University College Hospital, University College London Hospitals NHS Foundation Trust, London), Beatriz Lara (University Hospital, University Hospitals Coventry and Warwickshire NHS Trust, Coventry), Graham Miller (University Hospital of North Tees, North Tees and Hartlepool NHS Foundation Trust, Hartlepool), Sarah Haney and Laura MacKay (Wansbeck Hospital, Northumbria Healthcare NHS Foundation Trust, Ashington), Steve O'Hickey (Worcester Royal Hospital, Worcestershire Acute Hospitals NHS Trust, Worcester), Owen Dempsey (Aberdeen Royal Infirmary, NHS Grampian, Aberdeen), Matthew Embley (Forth Valley Royal Hospital, NHS Forth Valley, Larbert), George Chalmers (Glasgow Royal Infirmary, NHS Greater Glasgow and Clyde, Glasgow), Sarah Davies (Glan Clwyd Hospital, Betsi Cadwaladr University Health Board, Bodelwyddan), Ben Hope-Gill (University Hospital Llandough, Cardiff and Vale University Health Board, Penarth), Neil McAndrew (Wrexham Maelor Hospital, Betsi Cadwaladr University Health Board, Wrexham), Paul Minnis (Antrim Area Hospital, Northern Health and Social Care Trust, Antrim), and Karol Henry (The Ulster Hospital, South Eastern Health and Social Care Trust, Dundonald).

Conflict of interest: L.G. Spencer reports a small, one-off start grant from HQIP in 2013, and small, one-off grants for software from Boehringer Ingelheim and InterMune in 2014, during the conduct of the study; and in the last 12 months has given one lecture paid for by Roche, facilitated one 2-day leadership course paid for by Boehringer Ingelheim, and received travel support and a registration fee to attend ERS Congress 2019 from Roche. M. Loughenbury reports a small, one-off start grant from HQIP in 2013, and small, one-off grants for software from Boehringer Ingelheim and InterMune in 2014, during the conduct of the study. N. Chaudhuri reports a small, one-off starter grant from HQIP in 2013, and small, one-off grants for software from Boehringer Ingelheim and InterMune in 2014, during the conduct of the study; and in the last 12 months: Roche funding for attending ATS 2019, participation in advisory boards, presenting at UK Advances in IPF meeting, presenting at Roche European AIR meeting and presenting at international meetings, and Boehringer Ingelheim funding for attending ERS 2019, participation in advisory boards and a video for a clinical trial. M. Spiteri reports a small, one-off start grant from HQIP in 2013, and small, one-off grants for software from Boehringer Ingelheim and InterMune in 2014, during the conduct of the study. H. Parfrey reports a small, one-off start grant from HQIP in 2013, and small, one-off grants for software from Boehringer Ingelheim and InterMune in 2014, during the conduct of the study; an educational grant and costs for conference attendance from Boehringer Ingelheim, and an educational grant, lecture fees and costs for conference attendance from Roche, outside the submitted work; and she is founding trustee for Action for Pulmonary Fibrosis.

\section{References}

1 Ryerson CJ, Urbania TH, Richeldi L, et al. Prevalence and prognosis of unclassifiable interstitial lung disease. Eur Respir J 2013; 42: 750-757.

2 Raghu G, Chen SY, Yeh WS, et al. Idiopathic pulmonary fibrosis in US Medicare beneficiaries aged 65 years and older: incidence, prevalence, and survival, 2001-11. Lancet Respir Med 2014; 2: 566-572.

3 King TE Jr, Bradford WZ, Castro-Bernardini S, et al. A phase 3 trial of pirfenidone in patients with idiopathic pulmonary fibrosis. N Engl J Med 2014; 370: 2083-2092.

4 Richeldi L, du Bois RM, Raghu G, et al. Efficacy and safety of nintedanib in idiopathic pulmonary fibrosis. $N$ Engl J Med 2014; 370: 2071-2082.

5 Jo HE, Glaspole I, Grainge C, et al. Baseline characteristics of idiopathic pulmonary fibrosis: analysis from the Australian Idiopathic Pulmonary Fibrosis Registry. Eur Respir J 2017; 49: 1601592.

6 Raghu G, Rochwerg B, Zhang Y, et al. An Official ATS/ERS/JRS/ALAT Clinical Practice Guideline: Treatment of Idiopathic Pulmonary Fibrosis. An update of the 2011 clinical practice guideline. Am J Respir Crit Care Med 2015; 192: e3-19.

7 Zurkova M, Kriegova E, Kolek V, et al. Effect of pirfenidone on lung function decline and survival: 5-yr experience from a real-life IPF cohort from the Czech EMPIRE registry. Respir Res 2019; 20: 16

8 Galli JA, Pandya A, Vega-Olivo M, et al. Pirfenidone and nintedanib for pulmonary fibrosis in clinical practice: tolerability and adverse drug reactions. Respirology 2017; 22: 1171-1178.

9 National Institute for Health and Care Excellence. Diagnosis and management of suspected idiopathic pulmonary fibrosis. 2013. nice.org.uk/guidance/cg163. 
10 National Institute for Health and Care Excellence. Idiopathic pulmonary fibrosis in adults: Quality Standard (QS79). 2015. nice.org.uk/guidance/qs79.

11 National Institute for Health and Care Excellence. Pirfenidone for treating idiopathic pulmonary fibrosis Technology appraisal guidance [TA504]. 2018. nice.org.uk/guidance/ta504.

12 National Institute for Health and Care Excellence. Nintedanib for treating idiopathic pulmonary fibrosis Technology appraisal guidance [TA379]. 2016. nice.org.uk/guidance/ta379.

13 Navaratnam V, Fleming KM, West J, et al. The rising incidence of idiopathic pulmonary fibrosis in the U.K. Thorax 2011; 66: 462-467.

14 British Lung Foundation. The Battle for Breath. www.blf.org.uk/policy/the-battle-for-breath-2016 2016. Date last accessed: 9 December 2020. Date last updated: 2016.

15 Navaratnam V, Fogarty AW, Glendening R, et al. The increasing secondary care burden of idiopathic pulmonary fibrosis: hospital admission trends in England from 1998 to 2010. Chest 2013; 143: 1078-1084.

16 Hutchinson JP, McKeever TM, Fogarty AW, et al. Increasing global mortality from idiopathic pulmonary fibrosis in the twenty-first century. Ann Am Thorac Soc 2014; 11: 1176-1185.

17 Hutchinson J, Fogarty A, Hubbard R, et al. Global incidence and mortality of idiopathic pulmonary fibrosis: a systematic review. Eur Respir J 2015; 46: 795-806.

18 Raghu G, Collard HR, Egan JJ, et al. An official ATS/ERS/JRS/ALAT statement: idiopathic pulmonary fibrosis: evidence-based guidelines for diagnosis and management. Am J Respir Crit Care Med 2011; 183: 788-824.

19 Snyder L, Neely ML, Hellkamp AS, et al. Predictors of death or lung transplant after a diagnosis of idiopathic pulmonary fibrosis: insights from the IPF-PRO Registry. Respir Res 2019; 20: 105.

20 Spiteri M, Chang W, Chaudhuri N, et al. First insights from the BTS Idiopathic Pulmonary Fibrosis (IPF) Registry. Eur Respir J 2016; 48: Suppl. 60, PA2099.

21 Behr J, Kreuter M, Hoeper MM, et al. Management of patients with idiopathic pulmonary fibrosis in clinical practice: the INSIGHTS-IPF registry. Eur Respir J 2015; 46: 186-196.

22 Wuyts WA, Dahlqvist C, Slabbynck $\mathrm{H}$, et al. Baseline clinical characteristics, comorbidities and prescribed medication in a real-world population of patients with idiopathic pulmonary fibrosis: the PROOF registry. BMJ Open Respir Res 2018; 5: e000331.

23 Guenther A, Krauss E, Tello S, et al. The European IPF registry (eurIPFreg): baseline characteristics and survival of patients with idiopathic pulmonary fibrosis. Respir Res 2018; 19: 141

24 Doubkova M, Svancara J, Svoboda M, et al. EMPIRE Registry, Czech Part: Impact of demographics, pulmonary function and HRCT on survival and clinical course in idiopathic pulmonary fibrosis. Clin Respir J 2018; 12 : $1526-1535$.

25 Ferrara G, Carlson L, Palm A, et al. Idiopathic pulmonary fibrosis in Sweden: report from the first year of activity of the Swedish IPF-Registry. Eur Clin Respir J 2016; 3: 31090.

26 Fernandez-Fabrellas E, Molina-Molina M, Soriano JB, et al. Demographic and clinical profile of idiopathic pulmonary fibrosis patients in Spain: the SEPAR National Registry. Respir Res 2019; $20: 127$.

27 Kaunisto J, Salomaa ER, Hodgson U, et al. Demographics and survival of patients with idiopathic pulmonary fibrosis in the FinnishIPF registry. ERJ Open Res 2019; 5: 00170-2018.

28 Russell AM, Ripamonti E, Vancheri C. Qualitative European survey of patients with idiopathic pulmonary fibrosis: patients' perspectives of the disease and treatment. BMC Pulm Med 2016; 16: 10.

29 Cottin V. Current approaches to the diagnosis and treatment of idiopathic pulmonary fibrosis in Europe: the AIR survey. Eur Respir Rev 2014; 23: 225-230.

30 Kreuter M, Swigris J, Pittrow D, et al. The clinical course of idiopathic pulmonary fibrosis and its association to quality of life over time: longitudinal data from the INSIGHTS-IPF registry. Respir Res 2019; 20: 59.

31 Hewson T, McKeever TM, Gibson JE, et al. Timing of onset of symptoms in people with idiopathic pulmonary fibrosis. Thorax 2017; 73: 683-685.

32 Raghu G, Remy-Jardin M, Myers JL, et al. Diagnosis of Idiopathic Pulmonary Fibrosis. An Official ATS/ERS/JRS/ ALAT Clinical Practice Guideline. Am J Respir Crit Care Med 2018; 198: e44-e68.

33 Lynch DA, Sverzellati N, Travis WD, et al. Diagnostic criteria for idiopathic pulmonary fibrosis: a Fleischner Society White Paper. Lancet Respir Med 2018; 6: 138-153.

34 Fell CD, Martinez FJ, Liu LX, et al. Clinical predictors of a diagnosis of idiopathic pulmonary fibrosis. Am J Respir Crit Care Med 2010; 181: 832-837.

35 Song JW, Hong SB, Lim CM, et al. Acute exacerbation of idiopathic pulmonary fibrosis: incidence, risk factors and outcome. Eur Respir J 2011; 37: 356-363.

36 Gomes-Neto M, Silva CM, Ezequiel D, et al. Impact of pulmonary rehabilitation on exercise tolerance and quality of life in patients with idiopathic pulmonary fibrosis: a systematic review and meta-analysis. J Cardiopulm Rehabil Prev 2018; 38: 273-278. 